\title{
Publication trends in journal of clinical and experimental dentistry
}

\author{
Vidhi-Kiran Bhalla ${ }^{1}$, Sherin-Jose Chockattu ${ }^{2}$
}

\author{
${ }^{1}$ Senior Lecturer, Department of Conservative Dentistry and Endodontics ITS centre for dental studies and Reasearch, Ghaziabad, \\ Uttar Pradesh \\ ${ }^{2}$ Senior Lecturer ,Department of Conservative and Endodontics, Bapuji Dental College and Hospital, Davangere, Karnataka
}

Correspondence:

Department of Conservative Dentistry and Endodontics

ITS centre for dental studies and Research

Ghaziabad, Uttar Pradesh

vidhibhalla@gmail.com

Bhalla VK, Chockattu SJ. Publication trends in journal of clinical and experimental dentistry. J Clin Exp Dent. 2020;12(9):e857-63.

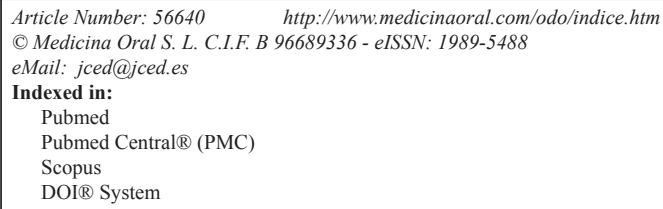

\begin{abstract}
Background: Journal of Clinical and Experimental Dentistry (J Clin Exp Dent; JCED) is an English language journal published by the Spanish Society of Oral Surgery, and has been online since 2009. It is indexed in PubMed Central and Scopus since 2012, with monthly publications since 2016. The purpose of this article was to review and analyse the publications in this journal since its inception, over a period of 11 years (2009-2019).

Material and Methods: This paper assessed the number, type and subjects of the articles published in the journal over 11 years. The institutions of the first authors, number of PubMed citations and the Hirsch (h5) index was assessed and analysed.

Results: The manuscripts published in JCED have gradually increased over the years, with Original research articles accounting for the bulk of contributions. The journal publishes articles mainly from the subjects of Oral Pathology and Operative Dentistry and Endodontics. Articles published in JCED are indexed in PubMed Central (since 2012), Scopus, DOI system, and Google Scholar. A country-wise mapping of the (first) author's institutions revealed significant contributions from researchers from all over the world. With an h5 index of 26, the journal was ranked among the top six multispeciality journals. The most cited articles were the literature reviews on common oral lesions (recurrent apthous stomatitis and candidiasis).

Conclusions: The journal has contributed to the growth of scientific literature pertaining to subjects from all the fields of dentistry. Over the past 11 years, JCED has served as a platform for large number of manuscripts in all the disciples of dentistry, from researches all over the world.
\end{abstract}

Key words: Publication trends, Journal of Clinical and Experimental Dentistry, Bibliometrics.

\section{Introduction}

Journal of Clinical and Experimental Dentistry (J Clin Exp Dent) is the official journal of the Spanish Society of Oral Surgery (SECIB) with the ISSN 1989-5844. This journal has been online since September 2009, under the leadership and guidance of Prof. José V. Bagán, the Editor-in-Chief (1). In the year 2010, the issues were published quarterly, and since 2011, the journal initiated bimonthly publications until 2016. From 2017 onwards, issues are put forth every month, and it continues this trend till date. This can be attributed to the spurt in manuscript submissions over the years. The journal is 
indexed in Pubmed and Pubmed Central (since 2012), Scopus, DOI system, and Google Scholar (1).

J Clin Exp Dent is a peer-reviewed, open access journal providing recent and innovative research and development pertaining to all the nine specialities of dentistry, which includes Periodontology, Community and Preventive Dentistry, Esthetic Dentistry, Biomaterials and Bioengineering in Dentistry, Operative Dentistry and Endodontics, Prosthetic Dentistry, Orthodontics, Oral Medicine and Pathology, Odontostomatology for the disabled or special patients, and Oral Surgery. Pertaining to the types of articles, the journal publishes original research, case reports and review articles (1).

The application of bibliometric data is useful measure to assess the performance of authors, scientific articles, journals or institutions $(2,3)$. Citation-based measures that enable this assessment include Impact Factor (IF; Clarivate Analytics' Journal Impact Factor) and the Hirsch index (h5-index). Impact factor is a reflection of the number of citations of the journal's articles during the preceeding two years. The h5-index attempts to measure the impact and productivity of the published work of the journal/ researcher over a period of five years (4).

An assessment is yet to be conducted on the nature of articles published in JCED and their citations, nor has been the journal been compared with other speciality journals. An analysis and study of publication patterns and citations of a journal is necessary for evaluation of the journal's contribution to the growth of scientific literature. Hence, the aims of the present article were: 1) to perform an assessment of the articles published from 2009-2019 based on their type, subjects and authorship; and 2) to analyse the citation of JCED journal articles and compare it with other speciality journals.

\section{Material and Methods}

From the year 2009 to 2019, using the official website of JCED (http://www.medicinaoral.com/odo/indice.htm) (5), the eleven volumes and fifty eight issues were analysed for number, type, subject of articles, the country of the first author, and the article citations (since 2012) in PubMed.

On the Google Scholar website, under "metrics", (https://scholar.google.com/citations?view_op=top_venues\&hl=en) (6) a search for "Journal of Clinical and Experimental Dentistry" was done to determine the h5 index or Hirsch index of the journal. Using the SCimago Journal \& Country Rankings website (https://www.scimagojr. com/journalrank.php?category=3501), (7) a search was made for the multispeciality journals and journals in the speciality of Restorative Dentistry/ Endodontics/ Oral Pathology, and their h5 indices were compared with JCED in Google Scholar. Considering the scope of the journal, all the relevant journals were selected and compared.

The aforementioned analysis was carried out by both the authors independently, with discrepancies being resolved by consensus.

\section{Results}

From 2009-2019, 10 volumes and 80 issues of the JCED journal were analysed. Initially, the number of articles published was highly variable; subsequently there was a consistent increase in the number over the years. The maximum number of articles (205) were published in 2017, pertaining to all the fields of dentistry, with maximum contribution from the speciality of Oral pathology $(32.3 \%)$ and Operative Dentistry and Endodontics $(17.8 \%)$. This was followed by articles from the fields of Oral surgery (11.4\%), Orthodontics (8.8\%), Prosthodontics (7.5\%), Community \& Preventive Dentistry (7.4\%), Periodontology (4.4\%) and Biomaterials and Bioengineeering (4.4\%). The journal received a minor contribution from the fields of Esthetic Dentistry (3.2\%), Odontostomatology for the disabled/ special patients $(1.3 \%)$, as well as Oral Medicine and Radiology (0.5\%) (Table 1). An analysis of the type of articles published revealed an overwhelming majority of Original research articles (66.8\%), followed by Case reports (20\%) and Reviews $(13.2 \%)$ (Table 2). A total of 30 systematic reviews have been published over the past 10 years.

A country-wise assessment was performed on the corresponding author's institution. Unlike in 2009, the year of inception of the journal where the vast majority of articles were from Spain, the succeeding years witnessed increasing contributions from other countries. By 2017, Asian nations (Iran, Turkey, Malaysia, India, Thailand, Japan and Saudi Arabia) accounted for the majority of the articles published, with increasing contributions from Europe (Italy, Portugal, Greece, France), Africa (Egypt, Nigeria, Libya) and the Americas (USA, Canada, Brazil). However, the contributions from Spain (the native country) still represented the majority (Fig. 1).

Articles published in JCED have been cited in PubMed (since 2012). The number of citations showed a sharp spike in 2014 with over 304 citations, including Original research, reviews and case reports. In general, original research articles have been cited more consistently than case reports and reviews (Fig. 2). The number of citations were analysed for each article, using the PubMed Website. The 10 most cited articles of JCED in PubMed and Google Scholar (as on Nov 2019) is given in table 3, Fig. 3 . The most cited articles have been literature and systematic reviews on the recent treatment aspects of oral lesions like candidiasis and recurrent apthous ulcers.

On comparing the h5 index of the journal to other multispeciality journals, endodontic and oral pathology journals, JCED ranks amongst the top six, with an h5 index of 26. Also, the $\mathrm{h} 5$ index was similar to Brazilian Oral Research journal and Journal of Conservative Dentistry. 


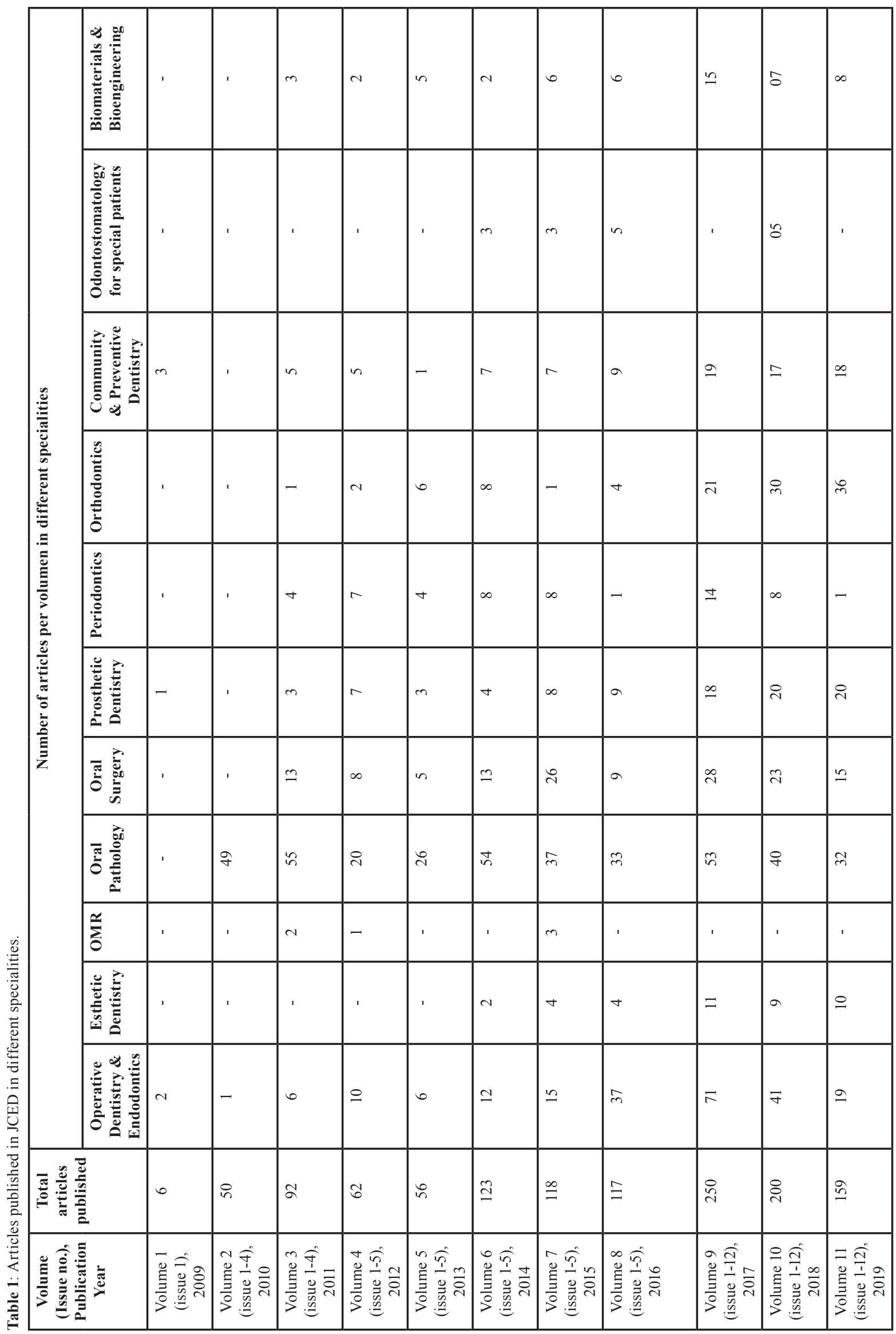


Table 2: Number of articles published in each category in JCED (2009-2019).

\begin{tabular}{|l|c|c|c|}
\hline \multirow{2}{*}{ Volume (Year) } & \multicolumn{3}{|c|}{ Number of articles published in each category } \\
\cline { 2 - 4 } & $\begin{array}{c}\text { Original } \\
\text { Research }\end{array}$ & Case Reports & Review \\
\hline Volume 1 (2009) & 6 & 0 & 0 \\
\hline Volume 2 (2010) & 10 & 32 & 8 \\
\hline Volume 3 (2011) & 31 & 35 & 26 \\
\hline Volume 4 (2012) & 31 & 15 & 16 \\
\hline Volume 5 (2013) & 40 & 11 & 05 \\
\hline Volume 6 (2014) & 76 & 26 & 21 \\
\hline Volume 7 (2015) & 87 & 13 & 18 \\
\hline Volume 8 (2016) & 82 & 21 & 14 \\
\hline Volume 9 (2017) & 190 & 37 & 27 \\
\hline Volume 10 (2018) & 152 & 35 & 09 \\
\hline Volume 11 (2019) & 119 & 21 & 19 \\
\hline
\end{tabular}

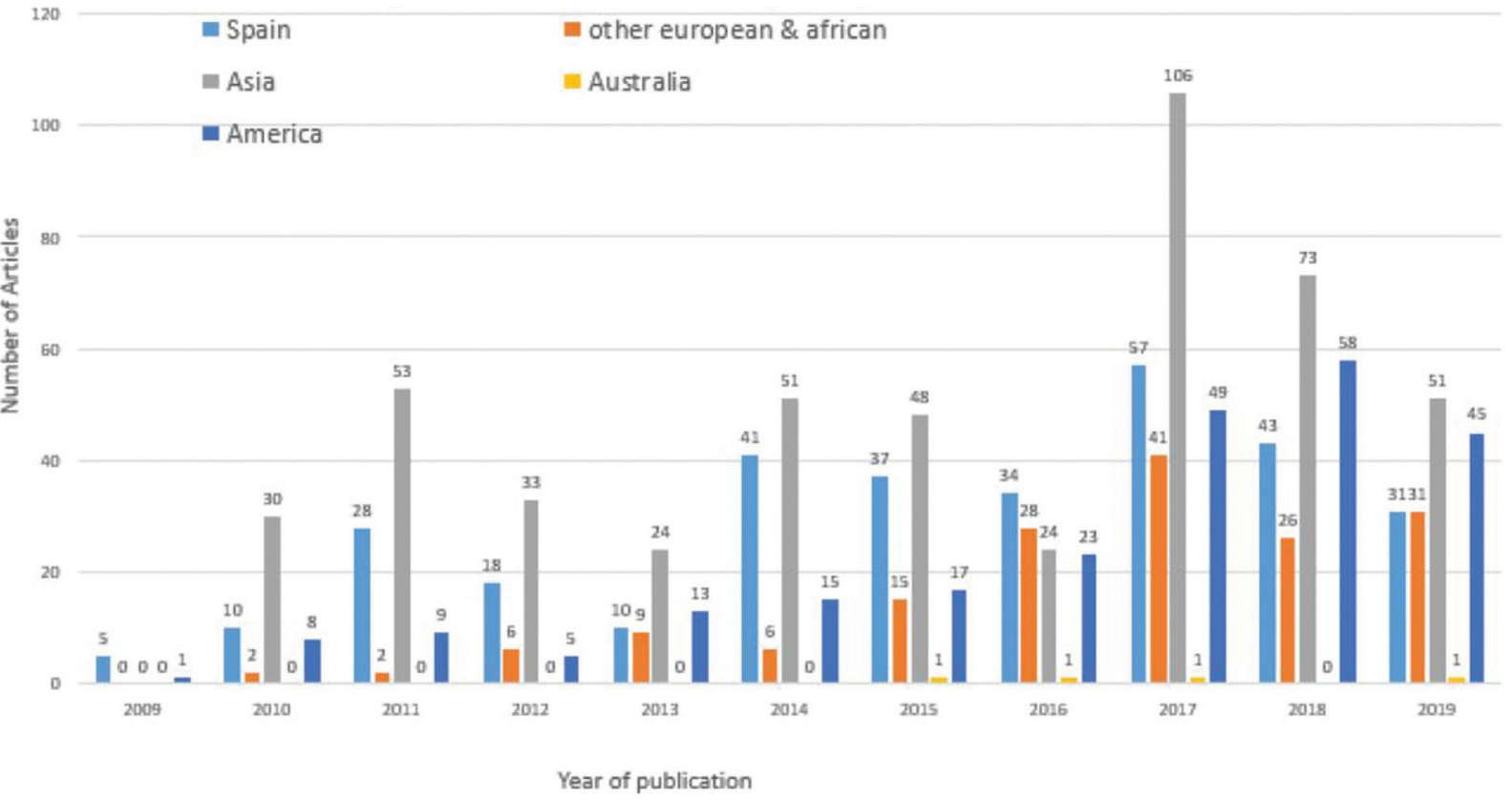

Fig. 1: Institutions of the first author by country.

\section{Discussion}

In our assessment of publication trends of JCED, over a period of 11 years (2009-2019), an important factor which was noted was the large number of quality peer reviewed original research articles, case reports and reviews. The manuscripts published span the whole spectrum of dentistry covering all the specialities and a wide range of topics. Although, the initial issues had maximum contribution from the speciality of Oral Medicine and pathology, the subsequent issues included a more uniform distribution of subjects, including a separate section for the diagnosis and management dental issue concerning of disabled or special patients.

JCED has witnessed a significant growth in scientific literature in the recent years. Whilst the bulk of articles have been from Spain, there has been a spurt in contribution from researchers of the other European nations, along with Asian and American nations. The trend of globalisation has been a significant factor in the journals success (33). The indexing of a journal in relevant and prominent databases provides visibility and allows dissemination of information published through such 


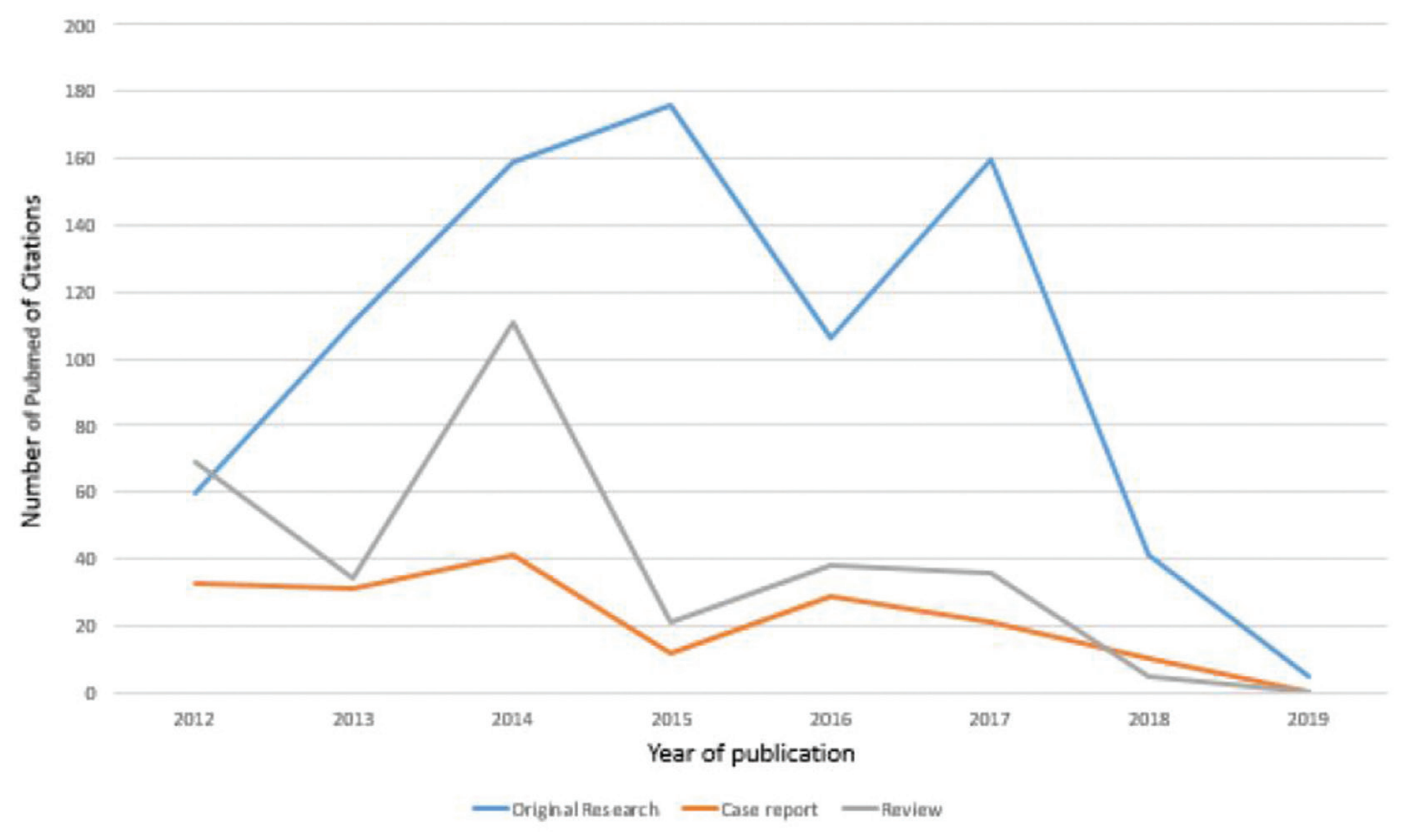

Fig. 2: Number of Pubmed Citations in JCED in each category (2012-2019).

Table 3: Number of citations of JCED in Pubmed and Google Scholar.

\begin{tabular}{|c|c|c|c|}
\hline $\begin{array}{l}\text { Number } \\
\text { of citations in } \\
\text { Pubmed } \\
\text { (Order of ranking) }\end{array}$ & Name of article & $\begin{array}{l}\text { Number of citations } \\
\text { in Google scholar } \\
\text { (Order of ranking) }\end{array}$ & $\begin{array}{l}\text { Name of } \\
\text { article }\end{array}$ \\
\hline $23(1)$ & Coronado-Castellote L et al. (8) & $105(1)$ & Belenguer-Guallar I et al. (10) \\
\hline $19(2)$ & Garcia-Cuesta C et al. (9) & $100(2)$ & Garcia-Cuesta C et al. (9) \\
\hline $17(3)$ & Belenguer-Guallar et al. (10) & $68(3)$ & Albero A et al. (27) \\
\hline $14(4)$ & Chaveli-López B et al. (11) & $60(4)$ & Agustín-Panadero R et al. (28) \\
\hline $13(5)$ & Patil S et al. (12) & $57(5)$ & Ata-Ali F et al. (29) \\
\hline $12(6)$ & $\begin{array}{l}\text { Chaveli-López B et al. (13) } \\
\text { Sánchez-Burgos R et al. (14) } \\
\text { Heravi F et al. (15) }\end{array}$ & $52(6)$ & Chaveli-López B et al. (13) \\
\hline 11(7) & $\begin{array}{c}\text { Acharya AB et al. (16) } \\
\text { Gainza-Cirauqui ML et al. (17) } \\
\text { Shahabi M et al. (18) }\end{array}$ & $48(7)$ & Chaveli-López B et al. (11) \\
\hline $10(8)$ & $\begin{array}{l}\text { Lawal AO et al. (19) } \\
\text { Amit G et al. (20) }\end{array}$ & $45(8)$ & Ata-Ali J et al. (30) \\
\hline $9(9)$ & $\begin{array}{c}\text { López-Frías FJ et al. (21) } \\
\text { Patil S et al. (22) } \\
\text { Alonso-Rodríguez E et al. (23) } \\
\text { Hattab FN et al. (24) }\end{array}$ & $39(9)$ & Patil S et al. (31) \\
\hline $8(10)$ & $\begin{array}{c}\text { Jodalli PS et al. (25) } \\
\text { Patil S et al. (26) }\end{array}$ & $38(10)$ & Mingarro-de-León A et al. (32) \\
\hline
\end{tabular}

journals to researchers in the field (34) Currently, JCED is indexed/ abstracted in PubMed and PubMed Central (since 2012), Scopus, DOI system, and Google Scholar (1).

The journal has publications from all the sub-speciali- ties of dentistry, the major contribution from the field of Oral Pathology, and Operative Dentistry and Endodontics. An analysis of the individual contributions of the specialities to the journal's scientific progress was not done. Additionally, we have taken into account only 


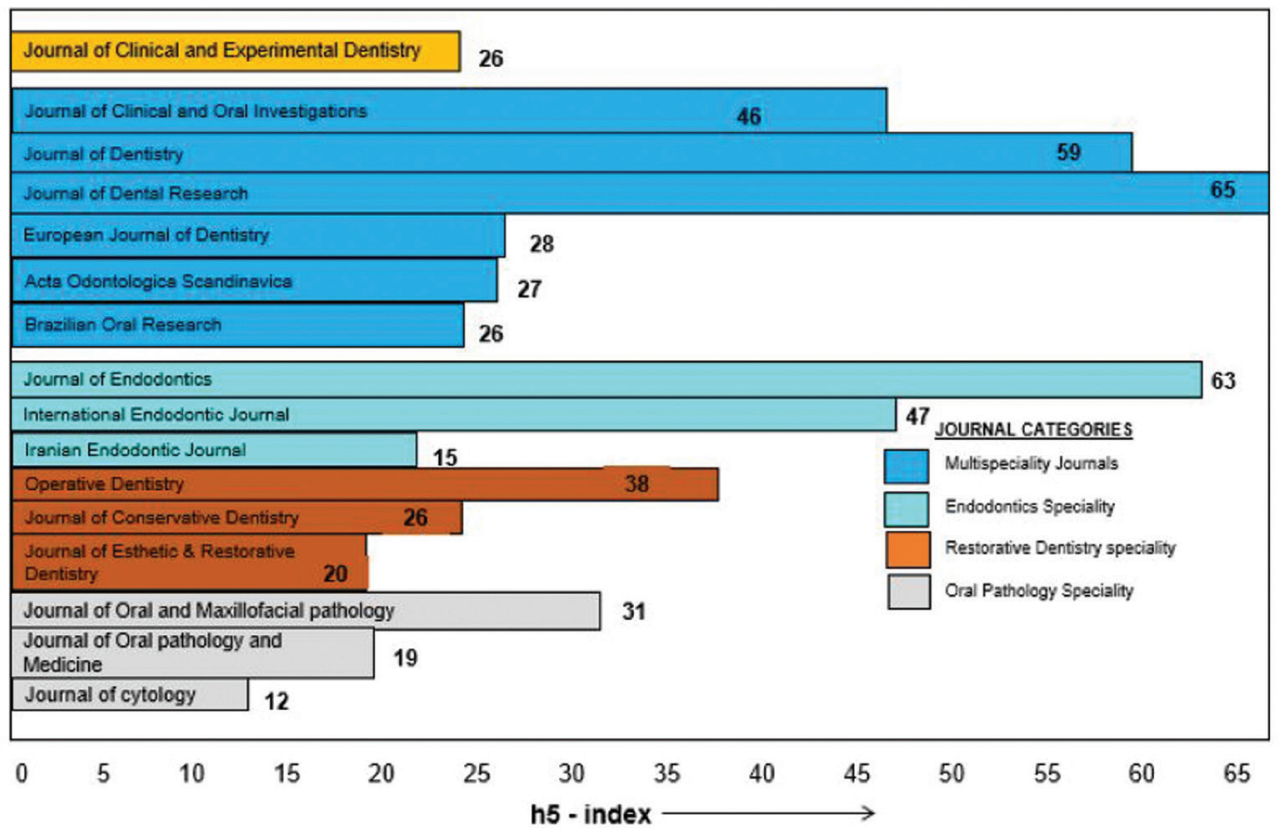

Fig. 3: Comparison oj JCED with other journals in the speciality.

the institution (or country) of the corresponding author, although in many articles, there have been contributions from authors of different countries.

The Impact factor (IF) published by the Thomson Reuters' annual Journal Citation Reports (JCR) is a popular and frequently used bibliometric index (35). It is fundamentally the average number of citations per year published over the previous 2 years, thereby measuring the journal's contribution and scope to the research field. However, the extent to which IF is appropriate for the evaluation of the quality of a specific article or journal and for the evaluation of individual or collective research achievements is highly debatable and often considered biased $(36,37)$.

The Hirsch index (h-index) is a measure of author's (or journal) output in terms of quality and consistency, based on the total number of publications and the total number of citations received of that work. It is traditionally measured over a five year period, hence it is referred to as "h5 index" (4). A comparison of the h5 index of JCED with other multispeciality journals revealed that JCED ranks amongst the top six multispeciality journals.

The number of citations in Pubmed showed a spike in 2014 with an overall 167 citations in original research, 96 citations in Reviews, and 41 in case reports. The general trend was more number of citations for research articles. Citations decreased thereafter, which was again followed by a slight increase in 2017.

An analysis of the most cited articles was done in PubMed and Google Scholar (Table 3). The most cited article on Google Scholar has been the literature review on the treatment of recurrent aphthous stomatitis; while on PubMed it has been the review on clinical and microbiological diagnosis of candidiasis. The information gathered in these reviews play a crucial role in updating the knowledge on the most common oral mucosal lesions encountered in clinical practice, relevant properties of dental materials, dental management of medically-complex patients, and forensic dentistry. Amongst the original research articles, prevalence of dental anomalies and retrospective studies on keratocystic odontogenic tumours have been the most cited. The journal has published numerous rare and interesting case reports on odontogenic tumours, oro-facial syndromes and unusual developmental disturbances. The most cited case report has been on schwannoma of the hard palate.

\section{Conclusions}

Over the last 11 years, since its genesis, JCED has served as a platform for a large number of manuscripts, in all the nine specialities of dentistry from researchers from all over the world. The unrestricted access and the nominal fee charged for publication has encouraged researchers and students from all over the world to submit their research papers and review articles to the journal.

\section{References}

1. Journal of clinical and experimental dentistry Sociedad Española de Cirugía Bucal. NLM Title Abbreviation: J Clin Exp Dent.ISSN:19895488 (Electronic); 1989-5488 (Linking). [Spain]: Medicina Oral. Not currently indexed for MEDLINE.

2. Gutiérrez-Vela MM, Díaz-Haro A, Berbel-Salvador S, Lucero-Sán- 
chez A, Robinson-García N, Cutando-Soriano A. Bibliometric analysis of research on regenerative periodontal surgery during the last 30 years. J Clin Exp Dent. 2012;4:e112-8.

3. Choudhri AF, Siddiqui A, Khan NR, Cohen HL. Understanding bibliometric parameters and analysis. Radiographics. 2015;35:736-46.

4. Mathur VP, Sharma A. Impact factor and other standardized measures of journal citation: a perspective. Indian J Dent Res. 2009;20:81-5. 5. National Center for Biotechnology Information (NCBI): NLM cata$\log$ :Journal of Clinical and Experimental Dentistry [Internet] Available from :https://www.ncbi.nlm.nih.gov/pmc/journals/2157/

6. Google Scholar. Metrics [Internet]. [place unknown]: Google Scholar; c2019 [cited 2019 Jul 20]. https://scholar.google.com/citations?view_op=top_venues\&hl=en.

7. SCImajo Institutions Rankings. SCImajo Journal \& Country Rank: dentistry journals [Internet]. [place unknown]: Scimago Lab; c2019 [cited 2019 Jul 20].https:/www.scimagojr.com/journalrank.php?category $=3501$

8. Coronado-Castellote L, Jiménez-Soriano Y. Clinical and microbiological diagnosis of oral candidiasis. J Clin Exp Dent. 2013 ;5:e279-86.

9. Garcia-Cuesta C, Sarrion-Pérez MG, Bagán JV. Current treatment of oral candidiasis:A literature review. J Clin Exp Dent. 2014;6:e576-82. 10. Belenguer-Guallar I, Jiménez-Soriano Y, Claramunt-Lozano A. Treatment of recurrent aphthous stomatitis. A literature review. J Clin Exp Dent. 2014;6:e168-74.

11. Chaveli-López B. Oral toxicity produced by chemotherapy: A systematic review. J Clin Exp Dent. 2014;6:e81-90.

12. Patil S, Doni B, Kaswan S, Rahman F. Prevalence of dental anomalies in Indian population. J Clin Exp Dent. 2013;5:e183-6.

13. Chaveli-López B, Bagán-Sebastián JV. Treatment of oral mucositis due to chemotherapy. J Clin Exp Dent. 2016;8:e201-9.

14. Sánchez-Burgos R, González-Martín-Moro J, Pérez-Fernández E, Burgueño-García M. Clinical, radiological and therapeutic features of keratocystic odontogenic tumours: a study over a decade. J Clin Exp Dent. 2014;6:e259-64.

15. Heravi F, Ahrari F, Mahdavi M, Basafa S. Comparative evaluation of the effect of Er:YAG laser and low level laser irradiation combined with CPP-ACPF cream on treatment of enamel caries. J Clin Exp Dent. 2014;6:e121-6.

16. Acharya AB, Surve SM, Thakur SL. A clinical study of the effect of calcium sodium phosphosilicate on dentin hypersensitivity. J Clin Exp Dent. 2013;5:e18-22.

17. Gainza-Cirauqui ML, Eguía-Del Valle A, Martínez-Conde R, Coca-Meneses JC, Aguirre-Urizar JM. Ancient Schwannoma of the hard palate. An uncommon case report and review. J Clin Exp Dent. 2013;5:e62-5.

18. Shahabi M, Ahrari F, Mohamadipour H, Moosavi H. Microleakage and shear bond strength of orthodontc brackets bonded to hypomineralized enamel following different surface preparations. J Clin Exp Dent.2014;6:e110-5

19. Lawal AO, Adisa AO, Olusanya AA. Odontogenic tumours: A review of 266 cases. J Clin Exp Dent. 2013 ;5:e13-7.

20. Amit G, Jps K, Pankaj B, Suchinder S, Parul B. Periodontally accelerated osteogenic orthodontics (PAOO) - a review. J Clin Exp Dent. 2012;4:e292-6.

21. López-Frías FJ, Castellanos-Cosano L, Martín-González J, Llamas-Carreras JM, Segura-Egea JJ. Clinical measurement of tooth wear: Tooth wear indices. J Clin Exp Dent. 2012;4:e48-53.

22. Patil S, Kaswan S, Rahman F, Doni B. Prevalence of tongue lesions in the Indian population. J Clin Exp Dent. 2013 ;5:e128-32.

23. Alonso-Rodríguez E, González-Otero T, Castro-Calvo A, Ruiz-Bravo E, Burgueño M. Parotid gland solitary fibrous tumor with mandibular bone destruction and aggressive behavior. J Clin Exp Dent. 2014;6:e299-302.

24. Hattab FN. Double talon cusps on supernumerary tooth fused to maxillary central incisor: Review of literature and report of case. J Clin Exp Dent. 2014;6:e400-7.

25. Jodalli PS, Ankola AV. Evaluation of knowledge, experience and perceptions about medical emergencies amongst dental graduates (Interns) of Belgaum City, India. J Clin Exp Dent. 2012 ;4:e14-8.
26. Patil S, Maheshwari S. Prevalence of impacted and supernumerary teeth in the North Indian population. J Clin Exp Dent. 2014;6:e116-20. 27. Albero A, Pascual A, Camps I, Grau-Benitez M. Comparative characterization of a novel cad-cam polymer-infiltrated-ceramic-network. J Clin Exp Dent. 2015;7:e495-500.

28. Agustín-Panadero R, Román-Rodríguez JL, Ferreiroa A, Solá-Ruíz MF, Fons-Font A. Zirconia in fixed prosthesis. A literature review. J Clin Exp Dent. 2014;6:e66-73.

29. Ata-Ali F, Ata-Ali J, Peñarrocha-Oltra D, Peñarrocha-Diago M. Prevalence, etiology, diagnosis, treatment and complications of supernumerary teeth. J Clin Exp Dent. 2014;6:e414-8.

30. Ata-Ali J, Ata-Ali F. Forensic dentistry in human identification: A review of the literature. J Clin Exp Dent. 2014;6:e162-7.

31. Patil S, Reddy SN, Maheshwari S, Khandelwal S, Shruthi D, Doni B. Prevalence of recurrent aphthous ulceration in the Indian Population. J Clin Exp Dent. 2014;6:e36-40.

32. Mingarro-de-León A, Chaveli-López B, Gavaldá-Esteve C. Dental management of patients receiving anticoagulant and/or antiplatelet treatment. J Clin Exp Dent. 2014;6:e155-61.

33. Rode Sde M. The advancing internationalization of our research. Braz Oral Res. 2008;22:291.

34. Grech V. The inclusion of an online journal in PubMed central - a difficult path. J Vis Commun Med. 2016;39:85-8.

35. Thompson Reuters. Scope Notes. 2012. Available: http://ipscience. thomsonreuters.com/mj1/scope/scope_scie/\#FY.

36. Scully C, Lodge H. Impact factors and their significance; overrated or misused? Br Dent J. 2005;198:391-3.

37. Ha TC, Tan SB, Soo KC. The journal impact factor: too much of an impact? Ann Acad Med Singapore. 2006;35:911-6.

\section{Conflict of Interest}

Non declared. 